\title{
Optimization of Independent College Students Evaluation of Teaching Assessment System Based on the PDCA Model
}

\author{
Sun Hongxia \\ Xinglin College, Nantong University
}

Funding source: Research on students' evaluation of teaching in Independent Colleges from the perspective of PDCA" (2018k221), scientific research fund project of Xinglin College of Nantong University in 2020

Abstract

Student evaluation of teaching is one of the important ways of independent college teaching quality evaluation, which has a positive practical significance to promote independent college teaching reform, and improve the teaching quality. In recent years, at the same time in the further carry out the work of student evaluation of teaching, more and more problem is highlighted. In this paper, from two aspects of roles and work itself, analysis of the present status of the independent college student evaluation of teaching. On this basis, student evaluation of teaching is introducing the theory of PDCA cycle, which is continuously correcting problems found in student work, optimizing the evaluation working process, , so to promote the communication between teachers and students cooperation, to achieve real actual effect of student appraisal evaluation of teaching

Keywords: PDCA, Student evaluation of teaching, Independent college, Optimization

DOI: $10.7176 / \mathrm{JEP} / 11-32-11$

Publication date: November $30^{\text {th }} 2020$

\section{I . Introduction}

Independent colleges are the exploration and innovation of the school-running mechanism and mode of higher education under the new situation, and they emerge as The Times require to fill the gap between undergraduate teaching or research universities and vocational and technical colleges in the university classification system. In recent years, with the expansion of the enrollment scale of independent colleges, their teaching quality has attracted more and more attention. The teaching quality of independent colleges directly reflects the running level of independent colleges and affects the quality of talent cultivation. Students, as important participants and receivers of knowledge in teaching activities, have more experience and say in teaching quality. The independent college objectively requires it to cultivate application-oriented talents with certain theoretical foundation, practical ability, practical ability, problem-solving ability and service for social development. However, in the actual teaching process, most independent colleges rely on the maternal teaching resources, curriculum system and teaching methods are similar. As an important means of teaching quality supervision [1], independent colleges have basically transplanted the common practice of parent universities in the practical operation process. Because of the particularity of the students in independent colleges and the difference of the talent training mode, the student evaluation and teaching system in the parent university is not suitable for independent learning to a large extent. Under this background, it is of practical significance to break away from the parent model and explore the evaluation index system suitable for the characteristics of independent college students and the orientation of training objectives.

\section{II . PDCA theory}

PDCA theory is a product quality control concept proposed by Dr. Hugh hart in the late 1920s, which was later applied and popularized by Dr. Deming in the field of product quality management in Japanese enterprises. PDCA advocates A basic principle of analyzing and solving problems: everything is done according to $\mathrm{P}, \mathrm{D}, \mathrm{C}$ and $\mathrm{A}$ [2].P-planning stage: analyze and diagnose the status quo, set improvement goals, and determine implementation and inspection plans. D- Implementation phase: work out the goals and programs according to the plan, and implement the improvement. C- Inspection phase; Monitor and refine the implementation process according to the target requirements, and report the operation results. A- Disposal stage: summarize the successful experience of the first three stages, convert them into standards for curing, and transfer the unsatisfactory parts and remaining problems to the next PDCA cycle for solving. In a word, PDCA cycle is to constantly find out the problems in the cycle, and then solve the problems, and then find out the outstanding problems follow the above four steps of the cycle, step up, at the same time the big cycle inside the small cycle, the small cycle is the big cycle. In foreign countries, there are few examples of educational institutions carrying out quality improvement based on PDCA concept, and most of them focus on administrative management system. Such as student satisfaction survey conducted at the university of Wisconsin (similar to the "student"), the school through the analysis the survey data and other information regarding student, find out the root of the problem of education, further clarify the process of education and the relationship between the teaching effect, and tries to reform, a series of reform has brought 
the student satisfaction increase year by year. An authoritative survey shows that the active learning rate of senior students in this school is $13 \%$ higher than the national average [3].In China, the application of PDCA in teaching quality management has a precedent. As early as 2000, Weihai Technical School adopted the "PDCA" cycle in the teaching process of advanced classes, making the quality of its graduates higher and higher each year.In recent years, the transfer and prevalence of "PDCA" method from business to education proves that the scientific nature and effectiveness of PDCA cycle have been deeply rooted in the public, feasible and effective. It can be seen that enterprise management and teaching quality management have certain differences in specific operational levels and individual details, but the basic principles and internal laws are the same [4].

\section{III. the independent college student evaluation teaching work present situation}

Most independent colleges do not have a long time to independently carry out student evaluation of teaching, and the implementation process is largely transplanted to use the content and form of the parent college student evaluation of teaching. This paper, from the perspective of PDCA, discusses the shortcomings of the current independent college's student evaluation and teaching work from four aspects of planning, implementation, evaluation and feedback, and deeply reflects on the existing problems, so as to further reform and improve.

\section{(I) Students' evaluation of teaching workflow}

At present, the working process of student evaluation of teaching is shown in Figure 1, which is carried out according to the three steps of plan, implementation and feedback. It is obvious that there are two significant problems. Second, the teaching situation is fed back to the teacher. As for whether the teaching problems that need to be improved will be improved, we cannot get the answer from the current working process.

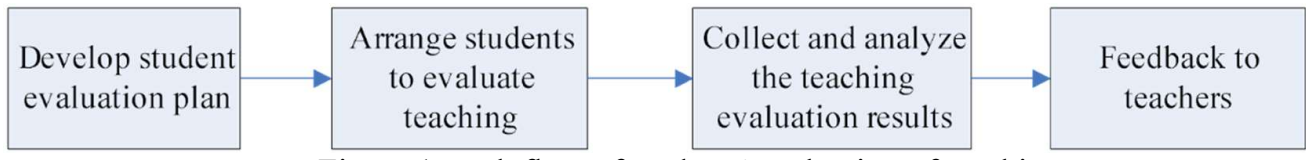

Figure 1 work flow of students' evaluation of teaching

(2) the problems existing in the student $\square$

1. Problems with the plan

(1) Evaluate the deviation of teaching objectivesThe survey found that most independent colleges have a vague understanding of the purpose of student evaluation of teaching, and the purpose of student evaluation of teaching is almost inseparable from the sentence "to improve the teaching quality of teachers". In-depth study can be found that the school in the final analysis is the talent training structure, the overall quality level of students directly affects the work of students after graduation. The ultimate purpose of teaching is to stimulate students' interest in learning, preserve students' all-round development, and improve the overall quality of talents cultivated by the school. This is the fundamental purpose of teaching, which is also the ultimate goal of student evaluation of teaching. $\square \square$

(2) Unscientific index system

At present, the student evaluation index system of most independent colleges is usually formulated by the administrative department, and the unified evaluation index is implemented throughout the college. A large number of studies have shown that there are statistically significant differences in the results of students' evaluation of teaching due to the different subject areas and course characteristics of the course. All teachers share the same teaching evaluation table, which cannot reflect the characteristics of different subjects and courses, and the teaching evaluation results are biased to a certain extent. At the same time, the study found most of the independent college student evaluation of teaching content to pay attention to the evaluation of teachers "teaching", from the perspective of teachers, to "speak" for the only goal, but seldom from the view of students "learning" to evaluate teachers' teaching, the content is in line with the teaching outline don't care, rarely on real gains the main standards to evaluate the students. In some schools, the index system has not changed since they began to evaluate teaching.

(3) Lack of plan audit

Student evaluation of teaching plan, including concept, objectives, indicators and policy in making finished, almost didn't review, plan, whether conform to the requirements of the actual evaluation, "arbitrary" execution, with its shortcomings and defects have not been found in a timely manner, so as to student evaluation of teaching results failed to achieve expected goals. In addition, even if there is some feedback after the development of students' evaluation plan, it has not been properly adopted and dealt with because of the lack of feedback system. As a result, the student evaluation and teaching plan with problems has not been corrected in time, and its operating efficiency will be greatly reduced. $\square \square \square \square$

2. Problems in the execution process

(1) Poor communication guidance

This is reflected in the lack of publicity and explanation in the early stage, and even the lack of reflection and 
discussion after the event. The publicity and presentation were not done in detail. Due to the propaganda work does not reach the designated position, causes the student to the online teaching evaluation, don't know what is the meaning of it, may affect them seriously to fill out: the teacher also because there is no publicity and afterwards reflection, make oneself not fully realize own teaching where the "poor", so may not be targeted for improvement.

(2) Poor timing

The independent college student evaluates the teaching time mostly to carry on in the final semester, the time lasts about one or two weeks. Because the evaluation of teaching time of the whole school focuses on which week is completed, the teaching quality of teachers may also exist "fluctuation phenomenon" in a semester, which is difficult to maintain a very stable one semester. In view of this, it is obvious that there will inevitably be bias in the use of concentrated time to judge the teaching quality of a semester.

(3) The result feedback is not timely

Some independent colleges "just ask students to have teaching, not its quality". In addition, quite a few independent colleges only carry out regular student evaluation of teaching, and the evaluation process is not standardized, and the data after student evaluation lacks scientific processing and timely feedback. Lack of process feedback mechanism. After the students fill out the questionnaire, they know nothing about other things. After receiving the evaluation, teachers almost know nothing about the follow-up operation process. Unless the quality of the teaching is really "poor", some colleges may give notice to the teachers and let them know "how the students rate the teaching". Some teachers felt that the feedback they were getting was "short on concrete advice".

3. Lack of evaluation of teaching process and results

Most independent colleges seldom arrange the evaluation of the process and results of students' evaluation of teaching. Even if a small part of the evaluation activities are just formalism, which cannot solve the essential problems of students' evaluation of teaching itself. At the same time, if the evaluation of students on the process of teaching is not strong enough, it will inevitably appear some deviation in the implementation, such as in the evaluation of students on teaching put forward inappropriate evaluation problems, the interpretation of the results of teaching evaluation is unreasonable, the evaluation of information has not been fully analyzed, draw fuzzy or controversial conclusions, etc. These biases will not only result in the waste of resources used by students to evaluate teaching, but also may provide misleading information and produce bad effects. Therefore, the evaluation of students' evaluation of teaching itself should be strengthened to ensure the quality of evaluation and improve the effectiveness of evaluation.

4. Weak feedback evaluation link

In the actual work of student evaluation of teaching, whether it is teaching feedback or the feedback of the whole process of evaluation of teaching, it is usually due to the lack of specific guidance, lack of direction in the process of specific improvement and implementation, and no effect. At the same time, the process of student evaluation and teaching in most independent colleges is not implemented, which disconnects the process of student evaluation and feedback, so that the feedback information and the process of student evaluation and teaching cannot promote each other. In a good feedback system of student evaluation and teaching, the feedback and the process of student evaluation and teaching should be achieved naturally and form a smooth feedback loop. The feedback information of each evaluation subject to students' evaluation of teaching may be inaccurate and unscientific.

Therefore, it is necessary to evaluate these feedback opinions appropriately. The lack of feedback and evaluation leads to unscientific and unreasonable information in the plan, process and conclusion of students' evaluation of teaching, thus making the effect of students' evaluation of teaching unsatisfactory.

\section{PDCA theory application in student work}

In 2007, the Ministry of Education and the Ministry of Finance jointly issued the Opinions on the Implementation of the Undergraduate Teaching Quality and Teaching Reform Project in Institutions of Higher Learning, aiming at strengthening the quality of undergraduate education and standardizing the management of college education. As one of the means of teaching quality evaluation, student evaluation of teaching is also a systematic project and a cycle. This article introducing PDCA quality management theory in the student management work, design "assessment plans and target of building", "assessment guidance and implementation of", "assessment process and result of evaluation", "assessment result of diagnosis and improve the" four steps, through continuous cycle of find and solve problems, constantly updated iteration, so that the students' work is constantly in the process of optimizing, forming an effective closed loop system, as shown in figure 2 . In order to achieve clearer and more effective management, we should improve student evaluation from a new Angle. 


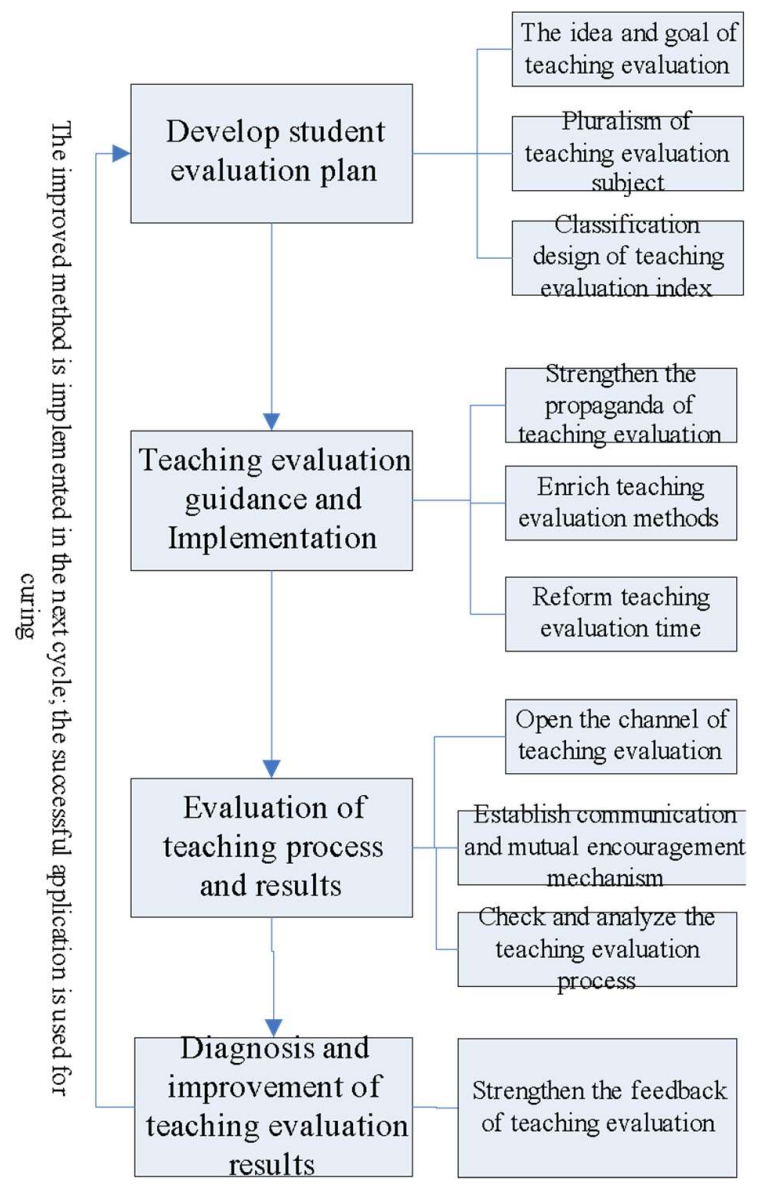

Figure 2 the optimized work flow of students' evaluation of teaching

(1) Evaluate the teaching plan and index construction

1. Comment on teaching philosophy and goalsAt present, no independent college has applied PDCA cycle theory in student evaluation and teaching work to implement the management concept of continuous improvement. The guiding ideology of "promoting construction by evaluation and promoting reform by evaluation" has not been well implemented in the system of student evaluation and teaching in independent colleges. All the time, only "evaluation" has been emphasized, while "construction" and "reform" have been neglected.

Before carrying out student evaluation of teaching, we must understand what the purpose of student evaluation of teaching is. It is found that most independent colleges in China still have a vague understanding of the purpose of students' teaching evaluation, and many colleges believe that the purpose of students' teaching evaluation is to improve teachers' teaching level. However, through in-depth study of domestic and foreign cases, we find that their common characteristics are the equal emphasis on teaching and learning, and the enhancement of good relationship between teachers and students. Student evaluation helps students to stimulate their own interest in learning, become the master of their own learning better, help teachers to discover their own defects in teaching skills, understand students' specific learning disabilities, and make teachers' guidance to students more targeted [6]. For example, Santa Clara City College of California believes that the purpose of student evaluation is to promote student learning and progress. They firmly believe that teaching quality is good only if the methods that promote students' learning are improved. Methods that can promote students' learning improvement can also promote the improvement of teachers' teaching skills [7]. These ideas should enlighten us.

2. Diversification of evaluation index design subjects

Students are the subject of learning and participate in the whole process of teaching. They are not only the participants but also the beneficiaries of teaching activities. They have the best understanding of teachers' teaching attitude, teaching level and teaching effect. But students due to the limitation of knowledge ability, understanding level, too much about some general language mastery, especially teaching attitude indicator, it is easy to cause the error of evaluation, therefore, in terms of teaching attitude indicator design, should take students as a starting point, descriptive language can be mastered with students easy to understand, for evaluation. However, administrators 
do not consider the participation of students in the development of student evaluation indicators, and some independent colleges even do not seek the opinions of teachers and other personnel. Through a large number of interviews, it is found that the design of student evaluation indexes is mostly made by the middle and senior managers of the Academic Affairs Office, and some are even the designers of the general evaluation system. Teachers and students basically do not give the right to participate in the design. The evaluation of the teaching administrators should correct their role and properly handle the relationship between the administrators, teachers and students. As Verboner said, "In order to make them have the highest efficiency, the administrators of the university must serve the needs of the scholars and scientists tem take serving teaching as the fundamental goal, from the beginning to the end. If teachers and students' participation in the design of evaluation indexes is fully considered, then the authenticity and effectiveness of students' evaluation of teachers' teaching is beyond comparison with that who make up the university from a supportive standpoint. At the same time, the formulation, implementation and feedback of the evaluation sysof other evaluation personnel [8].

3. Teaching index classification design

The teaching effect of different subjects has different emphasis, so the evaluation index should be customized according to the teaching nature and characteristics of teachers of different subjects, as well as the degree and specialty of students of corresponding subjects. Targeted to reflect different disciplines teachers' teaching situation, formulate appraisal table's assessment of the project and content as well as research subjects, and to explore the characteristics of teacher's flexibility, especially to study problems encountered in the process of course teaching of teachers, generated by means of combining the dialogue and exchanges, makes "students' evaluation of teaching" is more valuable. Special attention should be paid to highlight students' dominant position in teaching evaluation, and try to avoid indicators that students find difficult to directly feel and observe, so as to truly reflect students' requirements for good classroom teaching from the perspective of students' needs.(2) Evaluation of teaching guidance and implementation1. Strengthen the publicity of teaching evaluation.

Through various ways to promote the importance of student evaluation of teaching, let the teachers and students fully understand the benefits of appraisal, this requires college increase in front of the student evaluation of teaching organization propaganda work, mainly expounds the significance of learning evaluation of teaching and school the importance of this work, and for students about appraisal purpose, training of ability and attitude. As for students' evaluation of teaching, teachers should correct their own attitude towards students' evaluation of teaching, correctly understand the purpose and significance of evaluation of teaching, actively participate in the process of evaluation of teaching, in order to improve the development of their own correct treatment of students' evaluation of teaching results.2. Enrich teaching evaluation methods.

At present, independent college student evaluation of teaching work is generally carried out on the Internet. Although network evaluation of teaching has the advantages of quick and convenient, large-scale implementation, but there are problems such as opportunistic. By enriching the forms of students' evaluation of teaching, we can make up for its shortcomings to some extent. Such as in the implementation of the network evaluation of teaching at the same time, at the same time to carry out the form of paper and conversation. Online teaching evaluation is suitable for the whole school, paper may be more suitable for the class or professional unit, and the form of conversation may be more suitable for groups or individual objects. How to implement these forms, according to the actual situation, or at the same time or cross, the overall purpose is to understand the students from different sides of the real attitude towards teacher teaching, to get more real and effective evaluation of teaching information3. The reform of the appraisal time $\square \square$

Research found that my independent college students evaluation teaching only once a semester. This kind of one-time evaluation of teaching may lead to two kinds of phenomena: one is to cope with the phenomenon, that is, the school in order to cope with the inspection, a hurried evaluation of teaching, in order to the superior; Teachers in order to deal with the evaluation of teaching, is also a hasty preparation of a evaluation of teaching, after, is still the same. Second, the imbalance phenomenon, because of the concentrated time to complete the evaluation of teaching, it is difficult to supervise the classroom teaching in other time periods; That is, when the evaluation of teaching, the teacher to prepare, do not evaluate teaching, you can relax. Whether coping phenomenon or imbalance phenomenon, due to the evaluation of the number of teaching too single caused. Therefore, the current one-time evaluation of teaching should be changed to multiple evaluation of teaching, or even continuous evaluation of teaching. This can be done after each lesson, before, during, and after the semester, or after the unit. Persevere and make unremitting efforts.

(3) strengthen the student evaluation

1. Evaluation of open channel

At present, there are few evaluation channels for students to evaluate teaching in independent colleges, which generally adopt the form of symposium, but rarely use it. Forum format and frequency are very limited, it is difficult to take into account more people want to evaluate the right of students to evaluate teaching. Therefore, this kind of evaluation channel is relatively narrow. In fact, there are many places where comments can be created, such as the Internet, posters, forums, suggestion boxes or guest books. At the moment, students in independent 
colleges do not comment so much as find it difficult to make a complaint. Therefore, the evaluation office should be upgraded, and the way of evaluation should be open. If someone wants to comment, they can get what they want..

From the perspective of research, the main role of student evaluation is the office of academic Affairs, which is not only the organizer but also the evaluator. Students, teachers, enterprises, employers and other evaluation subjects, often do not consider. From the design, implementation and feedback of students' evaluation of teaching, there is a lack of evaluation voices from different subjects and Suggestions from multiple perspectives. Student evaluation of teaching has almost become an activity without any supervision and evaluation, even if there are problems also turn a blind eye. Therefore, the malpractice teaching evaluation process is not likely to get good teaching evaluation results, and more people should be encouraged to participate in students' teaching evaluation. So that the students evaluation of teaching activities really form such an atmosphere: there is a place to evaluate, everyone can evaluate. To create a positive evaluation culture on campus and to foster a healthy and harmonious development mode for improving the teaching quality assurance system.2. Set up the system of communication

In order to establish the mechanism of mutual communication and mutual encouragement, relevant systems should be formulated first to ensure the long-term continuity and effectiveness of the mechanism of student evaluation of teaching. According to the investigation and research, in many higher vocational colleges, evaluation activities are very rare; Moreover, the participants are relatively simple, most of them are organized by the office of Academic Affairs or counselors; Generally speaking, the content is also relatively broad, more about students' campus life, learning situation and other contents, but the real topic related to students' evaluation of teaching is less. It can be seen that the so - called symposium is not the real meaning of the student evaluation of the teaching exchange. Thus it can be seen that independent colleges have not yet established a mechanism to guide students in teaching evaluation.

Therefore, in order to establish the exchange and mutual encouragement mechanism of student evaluation of teaching, it is necessary to bring the evaluation of student evaluation of teaching into the system of school teaching quality assurance. Student evaluation of teaching in such aspects as design, process and result can be used as evaluation objects, the evaluation of the organizational form, time and personnel arrangement made specific provision, encourage everyone to public comments, 'each other, in order to establish a harmonious relationship between teachers and students, teachers and schools, graduates and unit of choose and employ persons relationship, so that the students' work on a real' to each other and self perfect healthy development track.

3. Timely check analysis $\square$

Independent colleges to the student evaluation of the evaluation of teaching inspection, generally relatively short of. Among the cases investigated in higher vocational colleges, only one has ever made relevant analysis report, while the other five have not. Therefore, basically far from the problem of timely evaluation and inspection. Student evaluation is an important part of teaching quality assurance system in higher vocational colleges, and also an important reform in teaching management. In the implementation process may encounter a variety of problems, so the need for the emergence of new situations and new problems in time to check differentiation will remove obstacles, strive for greater progress.

(1) Timely check and evaluate the teaching process

In the process of teaching evaluation, the plan is made, the plan is carried out, the evaluation is carried out and the result is handled. At each stage, it is necessary to check whether the expected goal is achieved and unify the idea and goal from the beginning to the end. The idea and goal of student evaluation in each school should have different characteristics of each school, but its core thought should be to ensure teaching quality and promote students' learning. Each extreme to the student evaluation of teaching timely inspection, can effectively prevent its process deviation. The inspection methods can be divided into two types, regular inspection and irregular inspection: regular inspection of the implementation effect of each stage and constraints, timely detection and solution of problems; Irregularly refers to the targeted inspection, aiming at a specific problem, accumulate experience, the remedy to the case, improve the effectiveness of the whole evaluation process.

(2) Analyze and evaluate the teaching process

At present, independent colleges do not pay enough attention to the analysis of the implementation process of student evaluation. Without a thorough analysis of the process of student evaluation of teaching, especially the existing problems, it is impossible to find out the root cause of the problems. The work of student evaluation of teaching cannot be improved, and the disease will always exist, which is bound to affect the evaluation results. Therefore, it is necessary to strengthen the inspection and analysis of students' evaluation of teaching. Even if there are no problems, through inspection and analysis, experience can be summarized; If there is a problem, you can learn from the lessons to make the best of it. Only form the analysis report system, develop the habit of selfsummary and reflection, it is possible to better promote the student evaluation of teaching work.

(4) strengthen the student feedback

According to the survey, about $60 \%$ of the respondents believe that the feedback from students on teachers is not specific enough, which makes teachers not know what specific problems exist in their teaching and how to 
improve it. Therefore, the concretization of feedback is an important step to help teachers improve the teaching quality. In colleges and universities in the United States, feedback on students' evaluation of teaching lists specific areas for teachers to improve. Teachers can learn about specific areas for improving teaching quality.

To be specific is to make your feedback specific and specific, rather than vague or lacking in references. According to the actual teaching characteristics or different subject requirements, some scientific and reasonable teaching Suggestions are put forward. For example, there should be different requirements for basic courses and specialized courses. For different teachers, some teaching Suggestions should be put forward according to their personality characteristics. To put forward targeted teaching Suggestions, we need to pay enough attention to teachers and their teaching activities at ordinary times, and have a profound understanding of their teaching style. In this way, the proposed Suggestions can be accurate and specific, and also show the evaluator's support and expectation for teachers' teaching improvement.

In the actual research, it is found that the feedback work of students' evaluation of teaching tends to fall into the tendency of heavy punishment and judgment. We should try our best to avoid the severe punishment of teachers without effective support measures, which may be not conducive to the real improvement of teachers' teaching quality, and their teaching confidence will be greatly bruised. $\square$

\section{V.Summary}

Student is one of the important means of independent college teaching quality evaluation, the PDCA quality management theory is introduced into the independent college student work, is to adapt to the needs of the development of the teaching quality management, through the PDCA cycle evaluation and feedback of appraisal process, not only improves the credibility of student appraisal of teaching results and effectiveness of the distance, and to a certain extent, improve the quality of the management of student work, in order to improve the teaching quality and improving the quality of talent accumulated certain experience, with other colleges and universities students evaluation work also play a role as a reference.

\section{Reference}

[1] Zhong Youtian, Wang Li, Sheng Yaohuan, Wang Xiaoli. Analysis of College Students' Evaluation of Teaching [J]. Educational Exploration,2008(3):75-76.

[2] Zhao Hong, Chen Liya. University Teaching Management Process Reengineering based on PDCA Cycle [J]. Modern Education Management,2015(2):76-80.

[3]Mónica Martínez-Gó, Jose Miguel Carot Sierra, José Jabaloyes,Manuel Zarzo. A multivariate method for analyzing and improving the use of student evaluation of teaching questionnaires: a case study[J].Quality \& Quantity,2011(45):1415-1427.

[4] Zhao Hong, Chen Liya. University Teaching Management Process Reengineering based on PDCA Cycle [J]. Modern Education Management, 2015(2):76-80.

[5] Yan Chengyuan. Research on the Optimization Strategy of "Student Evaluation of Teaching" in Colleges and Universities [J]. Contemporary Education Science,2013(5):43-45.

[6]Reggio Emilia, Patrizio Frederic, Davide Ferrari. Students' Evaluation of Teaching Effectiveness: Satisfaction and Related Factors[M]Statistical Methods for the Evaluation of University Systems [M] . Physica-Verlag HD, 2011:113-129.

[7] Meng Fan, HUANG Qiaoli. An Analysis of the Essence of college Students' Evaluation system [J]. Jiangsu Higher Education,2013(3):79-82.

[8] Liu Lihua, Li Mingjun. A Study on the Differences between Chinese and American College Students' Teaching Evaluation Questionnaires [J]. Education Exploration,2015(7):115-154. 